\title{
7. What works and why: collaborating in a crisis
}

\section{Shane Carmody}

The fundamental premise of this chapter derives from my experience as a practitioner of cross-government collaboration. We must seek ways to improve the processes of governing through collaboration if we want to successfully manage crises. To do so we need to be more effective in managing others and in making maximum use of their individual capacities to deal with the common threat or crisis situation. The lessons from crises involving the Federal Government, statutory organisations, emergency authorities, other governments and non-governmental organisations (NGOs) are that effective leadership is essential, as are clear identification of responsibilities and effective implementation of decisions.

My use of the term 'collaboration' is in its benign meaning: a context of cooperation and working or acting together, being helpful and doing as one is asked for the wider public good rather than cooperating or working with the enemy. With hindsight, however, I might observe that many of my pre-2000 experiences in intergovernmental collaboration often felt a lot more like trying to negotiate with the enemy than a helpful dialogue among friends.

I was a deputy secretary in the Department of Defence from 2001 to 2006. Defence is a large and immensely complex organisation of some 90000 military and civilian staff, with elements in all Australian states and territories, operating day and night throughout the year. It is a tough organisation to manage internally. Most senior managers have large personnel and financial accountabilities - and of course they need to negotiate successful outcomes across and outside the organisation.

While Defence 'operates' in all Australian states, it is worth noting that this is not really what Defence is set up to do. Defence is set up to fight wars, it is to be hoped, far offshore. And, like the Australian Federal Police's 'Fight crime together and win' mantra, the Australian Defence Force is above all established to 'fight wars and win'.

From 2000-06, I was a member of Defence's Strategic Command Group, chaired by the Chief of the Defence Forces and comprising the secretary, the Vice-Chief of the Defence Force, service chiefs and key senior civilian appointments. The group was established to deal with all operational matters. During my time there (under three successive Chiefs of the Defence Force), we were involved in numerous exceptional operations or crises. These crises included: the original 
Defence deployment to East Timor (which began in 1999 but was still in full flight in 2000); the aftermath of the 11 September 2001 attacks, including the Australian deployment to Afghanistan; the planning, negotiation, development and continuation of operations in Iraq after 2003; problems in Fiji; the Bali bombing of 2003; the Jakarta bombing of 2004; the second Bali bombing in 2005; the Asian tsunami in 2004; the Solomon Islands deployments one and two; Afghanistan again; East Timor again. This is not a comprehensive list but merely the main situations we dealt with in that period.

Fighting wars and undertaking military interventions are multidimensional. To be successful, it is important to understand the aim, to conduct detailed planning and to have good organisation and effective logistical support, including good sustainment for long and often unspecified periods. Anyone who has been in the military will know that there must also be-particularly in times of peace-constant training, repetitive development of doctrine and endless rehearsal. These three are in themselves features of military operational planning. These three - in contexts other than the one I am using here-will often be referred to as 'mere process'. The military knows, however, that this attention to the intricacies of preparation is what makes for effective military operations. Effective preparation wins wars. The military also knows that there is little discernable difference between the initial phases of a combat operation and the initial phases of a national crisis. In fact, in Australia, international crises are frequently allocated Defence operational names partly for that purpose, such as 'Bali Assist', 'Pakistan Assist' or the 'Regional Assistance Mission to Solomon Islands' (RAMSI, from 2003).

\section{Objectives in crisis management}

A decade ago there was much less understanding of the management of crises than is apparent today. Maybe that was because we did not perceive that there were many crises. Maybe it was also because, by and large, any such crises were considered more as local issues - or even state issues - than national issues.

Things have changed remarkably in the past decade. One of the great consultative trend-setting endeavours was the so-called Y2K threat (the supposed meltdown of computers and information technology systems at the turn of the past century). Of course, we all recall that nothing significant happened. What many people do not recall with equal clarity, however, is the level of cooperation and coordination engendered in the management of and approach to the impending crisis. In some ways, it was a unique experience across government and across the nation. It represented a transition to a more 'shared' sense of common accountabilities.

To most outside observers, nothing resulted except a lot of expenditure, empowerment of our information technology (IT) people and a realisation that 
we were critically dependent on systems we could not hope to understand. The reality is that since 2000, and in a process that started well before then, crisis planning and management have moved from the ad hoc to a highly sophisticated, evolved and coordinated process. While not without its faults, crisis management is now well past the 'let's just do something' mentality in the hope that it will deliver a result and ensure that we 'look like' we are contributing.

\section{From pre-existing arrangements to what works and why}

Crisis management in the late 1990s was an ad hoc and generally under-prepared system. The few standing institutional arrangements that did exist tended to be of recent origin. For example, the Strategy Policy Coordination Group began only in the 1990s, and the departments of Prime Minister and Cabinet (PM\&C), Foreign Affairs and Trade (DFAT) and Defence used this mechanism to manage immediate crises on a case-by-case basis (before the Secretaries' Committee on National Security and the National Security Committee of cabinet took on these responsibilities more formally). In these circumstances, $\mathrm{PM} \& \mathrm{C}$ had some moral suasion; DFAT had access and networks overseas; and Defence had the means and the human-resource capabilities.

We did not seem to need much more. Furthermore, there were a number of broader whole-of-government, interdepartmental committees (IDCs). IDCs, however, had a reputation for being the graveyard of good outcomes and the bastions of the protection and preservation of individual agency powers; this reduced their effectiveness.

My recent experience of collaborating across government organisations to manage crises has been one of sustained growth and increasing professionalism. There has been significant evolution in management processes, their sophistication and frequency, a broadening of involvement and, as a result, better outcomes. In the past few years, it would appear that almost everyone in these collaborative networks has worked out why they are there and what they need to be ready to do.

In the past few years, however, there has been a real change in the institutional architecture of crisis management. What has caused this could be the subject of debate: perhaps national security issues became bigger and more pressing, crises became more real and more numerous, perceptions of vulnerability were more pronounced or the need for greater preparedness in the face of national security threats was more imperative. Whatever the proximate cause, we experienced a large growth in specialist task forces charged with specific missions and objectives.

Drawing from this experience, I want to reflect on what has worked in this recent time frame and why. In particular, I will extract the objectives of effective 
crisis management — the opposite to just doing something (anything!) and hoping for the best.

As indicated earlier, the prime objectives of good crisis management mirror those for sound military operations. First, we must define the problem and identify what needs to be done. This sounds simple and logical but is often far from simple in the early stages of a crisis. How do the multiple agencies involved define the scale of a problem as it first appears or as initial information is channelled back to government? To illustrate with real cases, it was days after the Asian tsunami or the first Bali bombing when the scale and magnitude of the crisis was eventually apparent to policymakers at the centre of government. By then, much of the response work was well under way.

Second, clear, strategic leadership is necessary to identify the best organisation or organisational mix to progress the response or resolve the crisis. This involves dispassionately asking who is best placed to resolve the crisis or, alternatively, who should perform the lead agency role among the constellation of agencies likely to become involved. We should then identify the most efficient arrangements to establish effective command and control and make it happen in reality. Such control has to be effectively maintained as the situation develops - if for no other reason than to ensure that resources are not squandered. We need to constantly ask what sort of activity is required, when and how it is best managed and controlled. In collaboration with the main players, we need to identify and allocate resources to the two principal tasks emanating from the crisis: the 'understanding' and the 'doing'. Not all such considerations will be known at the start, so some inter-agency agility is required to meet the challenges as they unfold.

Third, the urge simply 'to do something' to indicate action or intent must be avoided. Such urges are generally wasteful of effort and expertise. Rather, the participants should look to building long-term capacity - or sustainment - so they can still manage the crisis when it slips to the routine, and to have better capacities with which to address future situations. Practical examples of this investment in long-term capacity include the long-running consultative measures in Iraq and East Timor.

Finally, we need to learn and apply lessons as we discover them in each new scenario. Crisis-management experience is, above all, evolutionary in nature.

I summarise the key practical activities that work well in crisis management across agencies, governments and organisations thus:

- $\quad$ early action, meetings or planning intervention

- well-established initial communications protocols

- a clear perspective and clear identification of the aim

- well-established, documented and rehearsed processes 
- clear accountabilities for those brought into the collaborative venture

- a commitment to resource sharing across agencies and to special initiatives

- a willingness by agencies to contribute staff (the Tsunami Task Force was a perfect example of this commitment, where staff external to the department were up and running in the DFAT Crisis Centre within hours)

- promoting and developing a feeling of 'we are all in it together'

- having only contributors present - no passengers

- individual agendas need to be sacrificed for the common agenda

- actively manage the media

- thinking about the 'end' at the 'beginning' and planning for it: repatriation, disengagement and a return to the pre-crisis status quo.

What inhibits effective crisis management? When responsibilities are not clear and no formal lead agency in charge has been selected, there is a lack of direction and the potential for inter-agency tensions. Collaboration does not work purely by consensus or when the scope of responsibility is uncertain. There is no room for excessive ideology in addressing crises. Crisis management is about clarity of understanding of the problem and clarity about what is needed to resolve it. Attempts to resolve the crisis will be impeded in the absence of a strategic perspective.

It is worth noting that some, but not all, of these inhibitors can be countered in advance. For example, it is imperative to define the problem accurately and early to avoid blurred objectives. It is also important to depoliticise problems, build trusting relations between agencies and put turf wars to one side. As indicated earlier, we can develop sound crisis-management arrangements and processes in leadership development. We can also seek to establish procedures in the absence of consistency.

For a long time, collaboration in a crisis was all about getting there and visibly doing something. More recently, we have taken on board more policy learning and adopted a much more sophisticated approach.

\section{Conclusions: lessons across government}

There are numerous important but often simple ways to improve collaboration across government. Knowing them and invoking them will lead to better overall outcomes not only in crisis management, but in all forms of collaboration.

In terms of continuing process and management responsibilities, we need to work out and identify the key organisational players who will attend most crises, most often, and be regularly at the centre of things, and ensure that they can speak with authority and act quickly. This line of authority and accumulated experience is not to be taken lightly. Officials in these organisations need to develop simple procedures and templates that suit different scenarios. If we rely on such accumulated experience and structured processes to start with, the 
chances are that the management of a specific crisis will start off well. Experience counts.

We also need to broaden responsibilities and accountabilities to take into account the expertise and local knowledge of specialised agencies. This is likely to include inter alia the Emergency Management Authority, the Australian Federal Police, health departments, Customs, state police, Coastwatch and the Attorney-General's Department. We cannot 'do' things from Canberra alone.

Emergency agencies need to regularly engage in simulated exercises and practise for the real event. They should routinely run realistic exercises, planning workshops, rehearsals, tests of capacities and inter-agency cooperation in order to reveal glitches. They need to document their learning and seek explicitly to apply the lessons of practice.

At the whole-of-government level, we need to embrace a multi-jurisdictional, multi-agency approach. This builds capacity across agencies, drills learning into agencies, develops individual skills and promotes thinking across disciplinary approaches. If we adopt this broader multi-agency focus, we begin to develop an effective network governance to deal with crises and similar situations. 